\title{
A REVOLUCIONÁRIA EXPERIÊNCIA DE DEFENSORAR POR MEIO DA SISTEMÁTICA DE ATUAÇÃO DO CENTRO DE REFERÊNCIA EM DIREITOS HUMANOS DA DEFENSORIA PÚBLICA DO RIO GRANDE DO SUL
}

THE REVOLUTIONARY EXPERIENCE OF ADVOCATING THROUGH THE SYSTEM OF ACTION OF THE human rights REFERENCE CENTER of the Public Defender of Rio GRANDE Do Sul

Mariana Py Muniz Cappellari

Defensora Pública do Estado do Rio Grande do Sul Doutoranda em Ciências Sociais pela Pontifícia Universidade Católica do Rio Grande do Sul (PUCRS) mpymuniz@hotmail.com

\section{RESUMO}

O artigo tem por intuito apresentar a revolucionária experiência de defensorar por meio da sistemática de atuação do Centro de Referência em Direitos Humanos da Defensoria Pública do Rio Grande do Sul, contribuindo para revelar um patamar de atuação da Defensoria Pública conforme ao texto constitucional e a normativa internacional, apresentando um acesso à justiça não mais vinculado meramente ao Poder Judiciário, mas de efetiva concretização de uma ordem jurídica justa, inclusive, em termos sociais, na medida do empoderamento e da expansão do exercício da cidadania. Para tanto, após apresentação do Centro de Referência em Direitos Humanos, bem como da sua esquemática de atuação, abordaremos a atividade de Defensorar por meio desse sistema, aliando referencial bibliográfico a tanto.

Palavras-chave: Defensoria Pública. Centro de Referência em Direitos Humanos. Acesso à Justiça. Cidadania. 


\section{ABSTRACT}

The purpose of this article is to present the revolutionary experience of advocating through the systematic work of the Human Rights Reference Center of the Public Defender's Office of the State of Rio Grande do Sul, contributing to reveal a level of action of the Public Defender according to the constitutional text and international regulations. an access to justice no longer linked merely to the Judiciary, but rather to the effective realization of a just legal order, including in social terms, to the extent of empowerment and expansion of the exercise of citizenship. Therefore, after presentation of the Reference Center on Human Rights, as well as its schematic of action, we will approach the Defensorar activity through this system, combining bibliographical reference to both.

Keywords: Public defense. Reference Center on Human Rights. Access to justice. Citizenship.

Data de submissão: 09/10/2017 Data de aceitação: 29/05/2018

\section{SUMÁRIO}

INTRODUÇÃO 1. DO CRDH/DPE/RS 2. O DEFENSORAR POR MEIO DO CRDH/DPE/RS. CONSIDERAÇÓES FINAIS.

\section{INTRODUÇÁO}

A emenda constitucional no. 80 de 2014, ao reconceituar a instituição Defensoria Pública, aos moldes do que então já havia sido produzido pela Lei Complementar no. 80/94, com as alterações empreendidas pela Lei Complementar $n^{\circ}$. 132/09, desvela um novo olhar institucional, muito mais sistêmico, na medida em que acentua que o acesso à justiça, função precípua da Defensoria Pública, direito humano fundamental, não se resume e tampouco se encerra no acesso ao Poder Judiciário. 
Muito pelo contrário, a autonomia que lhe projeta enquanto instituição contrapoder, ${ }^{1}$ bem como o fato de se revelar enquanto expressão e instrumento do regime democrático lhe alçam a efetiva participação nos processos decisórios de todos os Poderes da República e de definição de políticas públicas, contribuindo, inclusive, internamente para a confecção de políticas que empoderem e possibilitem o exercício de cidadania integral por parte dos vulneráveis, economicamente ou organizacionalmente.

Nesse sentido, a forma de atuação do Centro de Referência em Direitos Humanos da Defensoria Pública do RS (CRDH-DPE/RS) revela-se revolucionária, na medida em que ao trabalhar com o enfrentamento da violência, fenômeno complexo, através da oferta de atendimento multidisciplinar, busca a aproximação constante dos movimentos sociais e das lideranças comunitárias, em verdadeiro trabalho de rede, promovendo educação em direitos humanos, rompendo, assim, com a atuação da Defensoria Pública ainda adstrita à ideia de que o acesso à justiça se limita ao acesso ao Poder Judiciário, quando, na verdade o acesso que se requer e pleiteia é o acesso a uma ordem jurídica minimamente justa.

Enquanto instituição promotora de direitos humanos, cumpre à Defensoria Pública a missão de concretizar efetiva transformação social, a qual dentro de uma ordem dita democrática requer a instituição de políticas que efetivamente contribuam para o exercício concreto da cidadania. O empoderamento político e o conhecimento dos direitos são fundamentais a tanto, o que já o faz o CRDH-DPE/RS, razão pela qual a presente artigo tem por objetivo demonstrar o quanto o modelo de atuação do Centro de Referência cumpre com os objetivos e as funçôes da instituição, traduzindo um defensorar, por meio de um olhar sistêmico, que anseia por um acesso à justiça social.

\section{DO CRDH-DPE/RS}

A Defensoria Pública do Estado do Rio Grande do Sul tem para além de um dever institucional, um múnus constitucional de promoção da conscientização sobre o ordenamento jurídico e, por assim dizer, de conscientização sobre direitos básicos de cidadania e direitos humanos. Pensando nisso, em parceria com a Secretaria de Direitos Humanos da Presidência da República, implantou o Centro de Referência em Direitos Humanos (CRDH-DPE/RS), fortalecendo sua missão institucional de promover a informação e a cultura dos direitos humanos, garantindo a ampliação das condiçôes de acesso à justiça de cidadãos e cidadấs vítimas de violências, especialmente a violência

$\overline{1}$ PAIVA, C. C. Prática Penal para a Defensoria Pública, 2016. 
contra a mulher e a violência estatal, em Porto Alegre e Região Metropolitana.

No CRDH-DPE/RS atua-se na construção de estratégias para o enfrentamento e superação da violência e afirmação de Direitos Humanos. As suas atividades se iniciaram em 17 de janeiro de 2014 e o convênio tem vigência até março de 2018. Até o presente momento, somos a única Defensoria Pública do País a firmar convênio com a Secretaria de Direitos Humanos da Presidência da República (SDH/PR) para implantação de um Centro de Referência em Direitos Humanos. Tanto isso é verdade que a Comissão de Defesa dos Direitos da Pessoa Humana (CONDEGE) firmou termo de cooperação técnica com a SDH no ano de 2017, a fim de que as demais Defensorias Públicas do país sejam instadas à implantação de Centros de Referência aos moldes do nosso.

O CRDH-DPE/RS está localizado no Centro Histórico de Porto Alegre. A localização, em local central, próxima à Sede da $\mathrm{DPE} / \mathrm{RS}$, visa facilitar o acesso à população que se desloca de diferentes regióes vulneráveis da capital e região metropolitana (acessibilidade universal), a promoção de ações itinerantes e a articulação com a sociedade civil e lideranças comunitárias. Além disso, a sua territorialidade tem como foco principal a não institucionalização, permitindo maior diálogo com os movimentos sociais e as lideranças, os quais se utilizam do espaço no mais das vezes para a realização de reunióes e eventos.

O público-alvo das açóes desenvolvidas pelo $\mathrm{CRDH}$ abrange as vítimas de preconceito, discriminação, intolerância, maus-tratos, negligência e abandono, especialmente as mulheres em situação de violência doméstica e as vítimas de violência estatal (principalmente do sistema de justiça e segurança pública). Indiretamente, visa alcançar os familiares, as lideranças comunitárias, órgãos e agentes governamentais encarregados da implementação dos direitos humanos e cidadania, organizações da sociedade civil que atuam em direitos humanos e cidadãos(ãs) em geral. Assim, o trabalho do Centro representa o compromisso com a execução e continuidade de uma política pública de caráter permanente, totalmente inserida em sua missão institucional; no III Plano Nacional de Direitos Humanos e no Plano Nacional de Educação em Direitos Humanos.

O CRDH atenderá as vítimas, seja por demanda espontânea, seja por encaminhamento de algum outro serviço ou Instituição ou pelo Disque-acolhimento.

O Disque-acolhimento é um meio pelo qual os assistidos(as) entram em contato diretamente com o CRDH, por meio de ligação gratuita (0800-6445556), a fim de buscar as primeiras orientaçóes sobre o funcionamento do serviço, bem como esclarecer 
eventuais dúvidas que venham a surgir no curso de seu acompanhamento com a equipe do CRDH. O Disque-acolhimento tem abrangência para todo o Estado do Rio Grande do Sul.

O procedimento para os atendimentos, cujos dados coletados são sigilosos, é composto, em regra, por quatro fases interdependentes:

1a Fase - Atendimento inicial: Nessa fase são realizados a triagem e o cadastro. É uma análise da situação, do risco iminente e da necessidade de urgência no atendimento. A vítima recebe informaçôes e orientaçóes gerais sobre o CRDH-DPE/RS, sobre a rede de atendimentos a sua disposição e sobre possíveis estratégias de ação.

$2^{\text {a }}$ Fase - Acolhimento Multidisciplinar: $\mathrm{O}$ atendimento nessa fase é realizado por uma psicóloga e uma assistente social. É feita a escuta do(a) assistido(a) em situação de violência, identificada sua demanda específica, avaliado o risco do caso e, se necessário, pactuado um plano de segurança e iniciado um plano personalizado de acompanhamento. Esta fase de atendimento poderá ser realizada com a presença de Defensor(a) Público(a) ou analista processual para melhor elucidação das questóes jurídicas.

$3^{\text {a }}$ Fase - Atendimento Especializado: O objetivo dessa fase é aprofundar o diagnóstico preliminar elaborado pela equipe, a fim de identificar as demandas a serem tratadas nos outros tipos de atendimento, quais sejam: a) Atendimento Psicossocial, com psicóloga e/ ou assistente social, com o objetivo de oferecer um espaço de escuta, suporte e reflexão ao(a) assistido(a) vítima de violência com vistas à promoçáo do fortalecimento subjetivo, da autonomia e do protagonismo. Além de fornecer orientaçóes, encaminhamento para a rede de atendimento e de serviços sociais existentes, para possibilitar meios de acesso às políticas públicas e a efetivação dos direitos; e b) Atendimento Jurídico, com Defensor(a) Público(a), com o objetivo de oferecer orientaçóes jurídicas e acompanhamento dos procedimentos judiciais e extrajudiciais. Também nessa fase, a equipe realiza interlocução com a rede de atendimento para encaminhar questōes de atendimento psicológico, saúde, segurança, moradia, benefícios sociais, documentos, educação, trabalho/emprego, geração de renda.

$4^{a}$ Fase - Educação em Direitos: O CRDH-DPE/RS realiza variadas ações em Educação em Direitos Humanos, as quais se concretizam nos seguintes formatos: a) Programa de capacitação permanente PAZ COM VOZ, que consiste em oficinas gratuitas e abertas ao público (na programação das oficinas procuramos proporcionar a reflexão sobre os temas 
relacionados aos Direitos Humanos sob diferentes perspectivas, como mostra de filmes, mostra de trabalhos acadêmicos, oficinas lúdicas, debates e palestras), além do minicurso Virando a Página, destinado aos adolescentes privados de liberdade, conforme convênio entabulado com a Fundação de Atendimento Sócio-Educativo (FASE/RS); b) Palestras, debates e workshops promovidos pela sociedade civil; c) Açóes itinerantes (mutiróes de atendimento, orientaçôes e divulgação do $\mathrm{CRDH}$ ); d) Elaboração e distribuição de cartilhas; e, e) página do CRDH na rede social "Facebook" (https://www.facebook.com/ centroemdireitoshumanos), na qual são publicadas notícias atuais sobre direitos humanos, tais como resultados de pesquisas, reportagens, vídeos, divulgação de eventos, conquistas na seara dos direitos humanos, dentre outros. No que tange ao Programa PAZ COM VOZ, só no ano de 2016 realizamos mais de 13 oficinas.

Especificamente quanto à $4^{\mathrm{a}}$ fase, a equipe do CRDH-DPE/RS entende que a "Educação em Direitos Humanos" está fundada em uma perspectiva de olhar sobre o sujeito e suas múltiplas formas de ser, estar e viver no mundo, náo se restringindo a espaços institucionalizados de difusão de informaçóes (forma tradicionalmente associada à ideia de educação). Considerando que os direitos humanos consistem em uma perspectiva de respeito à alteridade e às múltiplas formas de existência, a equipe entende que educar em direitos humanos, diferentemente de um procedimento padronizado de trabalho, é um processo que pode se dar nos mais variados contextos de encontro com o outro. Desta forma, educar em direitos humanos, para a equipe, tem como diretriz estimular e animar o outro a refletir sobre sua condição no mundo e apropriar-se de sua condição de cidadão de direitos para, por meio dos seus mais variados instrumentais políticos e subjetivos, ativamente transformar sua vida. Por isso, nos processos educativos que atravessam os momentos de escuta e atendimento, a equipe procura guiar a escuta e a orientação sensibilizando para a formação de uma consciência crítica de si e dos processos imbricados na construção dos contextos violentos ou violadores de direitos em que aquele(s) sujeito(s) está(ão) inserido(s). Procura-se, nesse sentido, estimular a reflexão, a partir da própria história que traz o sujeito até o CRDH, sobre suas condições de inserção no mundo, os processos históricos e sociais que permeiam tal inserção, incidindo em uma consciência crítica sobre os próprios modos de viver, pensar, sentir e agir, em suas relaçóes com os outros e consigo.

Não há limitação quanto ao número de atendimentos, os acompanhamentos são realizados enquanto a equipe e/ou o(a) assistido(a) entenderem necessário. $\mathrm{O}$ desligamento do serviço de atendimento especializado somente se dará quando for verificada a superação da situação de violência, o efetivo empoderamento da vítima e o fortalecimento de 
mecanismos psicológicos e sociais. No entanto, a equipe reforça à(o) assistida(o) que, sentindo necessidade, poderá voltar a solicitar atendimentos neste CRDH-DPE/RS.

Em relação a dados numéricos, desde sua abertura até junho de 2017, o CRDH-DPE/RS tem 2305 assistidos cadastrados e já foram realizados 8831 atendimentos.

Tendo em vista as duas linhas de açóes principais a serem trabalhadas neste Centro de Referência, o combate à violência doméstica e à violação de direitos humanos inseridos no CRDH-DPE/RS, encontram-se dois núcleos especializados da Defensoria Pública, o Núcleo de Defesa dos Direitos Humanos e o Núcleo de Defesa da Mulher.

O Núcleo de Defesa dos Direitos Humanos da Defensoria Pública do Rio Grande de Sul atua desde 2009 na prevenção de violaçôes aos Direitos Humanos, na busca pelo restabelecimento nos casos em que ela já ocorreu e na educação na área, ou seja, na promoção do empoderamento de indivíduos e grupos sociais em situação de vulnerabilidade econômica, social e organizacional. Com este escopo, o Núcleo atua no âmbito institucional, estabelecendo diretrizes de atuação da Defensoria Pública na área, mediante a elaboração de projetos, enunciados e encontros de capacitação, bem como de açóes que articulem e apoiem a atuaçáo de todos os Defensores Públicos do Estado, na garantia de efetividade dos Direitos Humanos, inclusive com subsídios à eventual necessidade de postulaçáo perante organismos internacionais de defesa dos Direitos Humanos como os que compõem o Sistema Interamericano/OEA (Organização dos Estados Americanos) e o Universal/ONU (Organização das Naçóes Unidas).

Externamente, o Núcleo de Defesa dos Direitos Humanos atua prevenindo violações identificadas por meio de demandas ou grupos sociais vulneráveis (com os quais busca interação e articulação), restabelecendo os direitos atacados por outros particulares ou mesmo pelo Poder Público e promovendo a educaçáo em Direitos Humanos. Para tanto, maneja instrumentos judiciais como açóes individuais e coletivas (de âmbito estadual ou nacional), bem como extrajudiciais, notadamente o Procedimento Administrativo para Apuração de Danos Coletivos (Padac), onde são realizadas audiências públicas, reunióes conciliatórias entre pessoas e grupos de conflito, expedidas recomendaçóes para o restabelecimento de direitos, firmados a conhecida função de apoio e aparelhamento aos Defensores Públicos.

Comitês e comissões dos quais o Núcleo participa: 
1. Conselho Estadual de Direitos Humanos (CEDH);

2. Comissão de Defesa dos Direitos da Pessoa Humana (CONDEGE);

3. Conselho Deliberativo do Programa Estadual de Proteção, Auxílio e Assistência a Testemunhas Ameaçadas (CONDEL/PROTEGE);

4. Conselho Estadual da Pessoa Idosa (CEI);

5. Comissão Estadual de Erradicação do Trabalho Escravo no Rio Grande do Sul (COETRAE/RS);

6. Conselho Estadual LGBT;

7. Comitê Estadual de Atenção a Migrantes, Refugiados, Apátridas e Vítimas do Tráfico de Pessoas (COMIRAT);

8. Conselho Estadual do Programa de Proteção aos Defensores e às Defensoras dos Direitos Humanos (CEPPDDH/RS);

9. Comitê Intersetorial de Acompanhamento e Monitoramento da Política Nacional para População em Situação de Rua;

10. Conselho Estadual dos Direitos da Pessoa com Deficiência (COEPEDE);

11. Comitê Estadual contra a Tortura (CECT/RS);

12. Presidência da Rede de Direitos Humanos do Sistema de Justiça e de Segurança do RS;

13. Coordenação da Frente Estadual por uma nova política prisional.

O Núcleo de Defesa da Mulher (NUDEM) foi criado em novembro de 2008, com recursos do PRONASCI - Programa Nacional de Segurança Pública com Cidadania, por meio de Convênio entre a DPE/RS e a Secretaria de Reforma do Judiciário, em cumprimento à Lei Maria da Penha. A lei prevê a garantia do acesso aos serviços de Defensoria Pública, mediante atendimento específico e humanizado, a toda mulher em situação de violência 
doméstica e familiar. Compete ao Núcleo realizar açôes e atividades voltadas à defesa dos direitos das mulheres em situação de violência, em especial a doméstica e a familiar, que configuram violação aos direitos humanos, nos termos da Constituição, da Lei Maria Penha (Lei ${ }^{\circ}$. 11.340/06) e consoante documentos internacionais.

Um dos mais relevantes diferenciais da atuação do NUDEM, e, de forma mais ampla, do CRDH/DPE-RS, é a estratégia de empoderamento das mulheres em situação de violência, que não se restringe à defesa e proteção frente ao ato violento. A partir dessa perspectiva, o Núcleo busca: a) Realizar atendimento sensível, humanizado e especializado; b) Realizar trabalho em parceria e articulado com a rede de proteção às mulheres, do Município, Estado, e Uniáo; c) Incidir ativamente nos espaços de debates de políticas públicas; d) Compor equipe multidisciplinar para a prestação de atendimentos; e, e) Realizar oficinas e capacitaçôes sobre o tema com os mais diversos públicos. O Núcleo atua por meio de capacitações, palestras, participação em audiências públicas, entrevistas, participação permanente na Rede Lilás, apoio aos Defensores Públicos e outras instituiçôes (mediante trocas de experiências e materiais), mutiróes de atendimento e disseminação do tema.

Por fim, cabe ressaltar que, nesses cerca de três anos e meio de atuação do CRDH/DPERS, nunca se teve notícia do falecimento de qualquer assistido por motivo correlato às violências/violaçôes de direitos humanos atendidas neste Centro.

\section{O DEFENSORAR POR MEIO DO CRDH/DPE-RS}

A Emenda Constitucional de no. 80 de 2014 traz para o texto constitucional, nos termos do seu artigo 134, aquila que já fazia referência a LC no ${ }^{\circ}$. 80/94, mormente após as alterações procedidas pela LC no ${ }^{\circ}$ 132/09. A instituição Defensoria Pública torna-se uma instituição permanente, cumprindo-lhe como expressáo e instrumento do regime democrático, a orientação jurídica, a promoção dos direitos humanos e a defesa dos necessitados, de forma integral e gratuita, em todas as instâncias.

Sinaliza-se, assim, a ampliação do parâmetro de atuação da Defensoria Pública, com a inclusão da defesa dos direitos coletivos, a promoçáo dos direitos humanos, a permanência, que indica impossibilidade de extinção, mormente porque cumpre com um direito humano fundamental que é o acesso à justiça; e é o fato de ser expressão e instrumento do regime democrático, o que lhe impóe a obrigatoriedade de defesa da democracia, seja 
interna, quanto externamente. ${ }^{2}$

Não se fala há muito em uma assistência judiciária, limitada ao acesso ao sistema de justiça, mas sim jurídica, integral, que possibilite não apenas o atendimento individual, mas que focalize na integralidade e na complexidade da pessoa que chega à Defensoria Pública, buscando orientação, capacitação, educação em direitos, ${ }^{3}$ conscientização, atendimento multidisciplinar e empoderamento para o exercício efetivo de cidadania.

$\overline{2}$ SOUSA, J. A. G. de. (Coord.). Uma Nova Defensoria Pública Pede Passagem. Reflexóes sobre a Lei Complementar 132/09, 2012. Nas palavras de Adriana Fagundes Burger e de Christine Balbinot in A nova dimensão da Defensoria Pública a partir das alterações introduzidas pela Lei Complementar no 132 na Lei Complementar no 80/94: “(...) a partir da publicaçâo da Lei Complementar no 132, a Defensoria Pública recebe adensamento nas suas atribuiçôes, passando a ser considerada "expressão e instrumento do regime democrático", caracterizando um salto evolutivo da Instituição. A presença da Defensoria Pública melhor qualifica a democracia e promove a inclusão das classes sociais que historicamente restavam distantes do acesso à Justiça. A complexização das relações sociais exige do Estado novas e mais versáteis Instituiçôes que possam atender aos anseios da população. A Instituição viabiliza, quando necessário, a postulação, seja judicial ou extrajudicial, com a utilização dos meios e recursos adequados à efetividade dos direitos, tornando-se, portanto, instrumento do Estado Democrático de Direito, na medida em que busca a realização dos direitos assegurados aos cidadáos. Ou seja, a Defensoria Pública transmuda-se mais uma vez, daquela Instituiçáo destinada a prestar atendimento jurídico integral e gratuito, para a expressão e instrumento de realização do regime democrático. A definiçâo elucida a vinculação, realizada pelo legislador constituinte, de que a democracia somente vinga em um Estado que respeita a dignidade da pessoa humana, e a Defensoria Pública, nesse contexto, deve ser considerada essencial ao processo de concretização dos direitos conferidos à pessoa humana. (...).” p. 2/3.

3 SOUSA, J. A. G. de. (Coord.). Uma Nova Defensoria Pública Pede Passagem. Reflexóes sobre a Lei Complementar 132/09, 2012. Nas palavras de Adriana Fagundes Burger e de Christine Balbinot in A nova dimensão da Defensoria Pública a partir das alteraçôes introduzidas pela Lei Complementar $n^{\circ}$ 132 na Lei Complementar no 80/94: “(...) o Defensor Público passa a ser considerado também um agente de educação jurídica, sendo uma das suas atribuiçôes institucionais a divulgaçáo dos direitos humanos. $\mathrm{O}$ conhecimento acerca dos direitos e deveres de cada um não só previne litígios, como também enseja maior reflexão sobre os atos da vida. (...) Assim, reconhece-se o poder-dever do Defensor Público de dialogar com os assistidos, disseminando o conhecimento jurídico, bem como a competência e atribuição da Instituição para a promoção dos direitos humanos, capacitando a população para o exercício da cidadania. Ora, se a difusão dos direitos humanos passa a ser considerada atribuição dos Defensores Públicos, ela naturalmente tem como consequência uma nova consciência nos cidadáos, que se reconhecem como sujeitos de direitos. E, cientes deste conhecimento, evidentemente passarão a exigir a sua implementação pelo Poder Público. O aprendizado não é um fim em si mesmo, mas tem por objetivo a intervenção na realidade social, com o objetivo de transformação. A educação sobre os direitos pode transformar a compreensão do contexto onde o indivíduo vive, o papel das Instituições, as possibilidades e as limitações próprias do ser humano, gerando um agir refletido sobre os atos da vida. (...).” p. 6/7. 
A atuação na preservação e reparação dos direitos das vítimas de violência ${ }^{4}$ possui interlocução com a promoção dos direitos humanos, na medida em que objetiva rever condutas ilícitas, bem como reparar minimamente, por meio de indenização, o dano causado, além, é claro, dentro do espectro de promoção dos direitos humanos, fomentar políticas públicas que se voltem à efetividade desses direitos, fiscalizando as já existentes e dando voz aos vulneráveis, por meio da participação em conselhos de direitos, a qual lhe permite ampliar o espectro da realidade violatória destes direitos, por meio da aproximaçáo e da escuta sempre atenta dos movimentos sociais e das organizaçóes da sociedade civil.

É nesse contexto que se insere o CRDH/DPE-RS, conforme podemos observar. A sua sistemática de atuação cumpre com todos os objetivos da Instituição Defensoria Pública, nos termos do artigo $3^{\circ}-A$ da LC $n^{\circ}$. 80/94, pois o foco no enfrentamento da violência, enquanto fenômeno complexo que é, faz com que as funçóes institucionais da Defensoria Pública sejam potencializadas, ofertando-se acolhimento integral, por meio de um atendimento multidisciplinar, o qual permite a escuta, o empoderamento, a conscientizaçáo, a educação em direitos, fortalecendo a pessoa em sua totalidade enquanto ser humano que é, inclusive, com a confecção de planos de segurança, dependendo do caso em concreto.

Além disso, a realização de um trabalho em rede tem por intuito a fiscalização, bem como proporcionar tensão nos demais órgãos, fortalecendo e buscando o cumprimento de políticas públicas já estabelecidas, para além da sugestão da confecção de políticas novas, as quais atendam às necessidades da população vulnerável - que se vê dentro dos parâmetros das 100 Regras de Brasília -, consistindo a vulnerabilidade em algo bem mais além do critério meramente econômico, na medida em que vinculada a idade, gênero, estado físico ou mental, etnia, cultura, migração, pobreza, privação de liberdade, entre outros, que são circunstâncias que encerram maiores dificuldades para exercer com

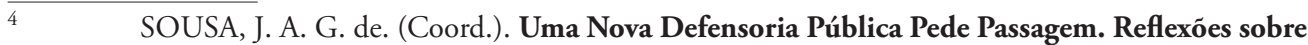
a Lei Complementar 132/09, 2012. Nas palavras de Adriana Fagundes Burger e de Christine Balbinot in A nova dimensão da Defensoria Pública a partir das alteraçóes introduzidas pela Lei Complementar no 132 na Lei Complementar no 80/94: “(...) Como resultado da atuação na difusão dos direitos humanos, o Defensor Público deve dar uma resposta, dentro do ordenamento jurídico, para aqueles que, de alguma forma, sofreram opressão, seja por parte do Estado ou não, observando a eficácia horizontal e vertical do ordenamento jurídico. A ênfase na reparação dos direitos violados tem como objetivo amenizar as consequências da violência, obtendo uma reparação que, se efetivamente não irá apegar a lembrança do ocorrido, poderá responder à dor sofrida com o recebimento de merecidas indenizaçôes. (...) A reparação por meio de indenizaçóes é medida mínima que o Estado pode oferecer ao ofendido. Essa atividade assume importância, primeiro, porque recupera a confiança do cidadão no ordenamento jurídico, apagando a sensação de impunidade e inoperância do Estado para com a satisfaçáo das suas necessidades. E mais, promove a paz social na medida em que os assistidos passam a confiar em que o Estado pode operar em seu favor (e não apenas contra eles), afastando a necessidade de vingança privada. (...).” p. 7.
} 
plenitude, ante o sistema de justiça, os seus direitos.

Nas palavras de Rocha:

A razão de existir da Defensoria Pública é o ser humano em condição de vulnerabilidade, cabendo-lhe, enquanto serviço público, adotar as providências jurídicas e políticas, extrajudiciais e judiciais a conferirlhe a dignidade necessária a bem viver. Não interessa apenas ao seu Usuário, mas a toda a sociedade, diante da indivisibilidade dos direitos humanos e da interligação que caracteriza a sociedade contemporânea. ${ }^{5}$

No contexto de uma nova "escravidão", conforme bem resume Rocha, de uma escravidão rebatizada, uma vez que não se pode considerar livre quem não tem onde morar, quem não pode se expressar livremente, quem não teve acesso a um julgamento justo, quem não é ouvido em projetos que lhe atingem, entre outros, a aproximação da Defensoria Pública aos movimentos sociais, às suas lideranças, bem como às organizaçóes da sociedade civil, é de crucial e fundamental importância, o que é objeto de extrema atenção por parte do CRDH/DPE-RS.

A sociedade civil e os movimentos sociais são os grandes responsáveis pela construção dos direitos humanos, a constante troca e compartilhamento de ideias com os movimentos, são o que permite à Defensoria Pública oxigenar-se democraticamente, não se encastelando na burocracia que é inerente ao sistema de justiça.

Boaventura de Sousa Santos descreve com propriedade o sistema de justiça, focando, inclusive, no ensino do direito e na formação profissional, revelando o que observamos na prática, que o sistema judicial foi criado, não para um processo de ruptura, de inovação, mas para um processo de continuidade, de continuidade das desigualdades, diríamos.

Santos acentua que nesse sistema domina uma cultura normativista, técnico-burocrática, assente em três grandes ideias: a autonomia do direito, enquanto sendo o direito um fenômeno autônomo em relação ao que ocorre na sociedade; uma concepção restritiva desse direito, de ser apenas o que está nos autos do processo; e uma concepção burocrática ou administrativa dos processos, que se manifesta de múltiplas formas: por meio da prioridade do direito civil e penal; de uma cultura generalista; da desresponsabilizaçáo sistêmica, com a transferência de culpa para fora do sistema, ou seja, o problema nunca

5 ROCHA, A. S. da. Defensoria Pública. Fundamentos, Organizaçáo e Funcionamento, 2013. 
é conosco; o privilégio do poder, na medida em que não se veem os agentes do poder em geral como cidadáos com iguais direitos e deveres; o refúgio burocrático; a independência como autossuficiência; e o que chama de sociedade longe.

Nesse sentido,

\begin{abstract}
A sexta manifestação desta cultura normativista técnico-burocrática é ser, em geral, competente a interpretar o direito e incompetente a interpretar a realidade. Ou seja, conhece bem o direito e a sua relaçáo com os autos, mas não conhece a relação dos autos com a realidade. Não sabe espremer os processos até que eles destilem a sociedade, as violaçóes de direitos humanos, as pessoas a sofrerem, as vidas injustiçadas. Como interpreta mal a realidade, o magistrado é presa fácil de ideias dominantes. Aliás, segundo a cultura dominante, o magistrado não deve ter sequer ideias próprias, deve é aplicar a lei. Obviamente que não tendo ideias próprias tem que ter algumas ideias, mesmo que pense que náo as tem. São as ideias dominantes que, nas nossas sociedades, tendem a ser as ideias de uma classe política muito pequena e de formadores de opiniáo, também muito pequena, dada a grande concentração dos meios de comunicação social. E é aí que se cria um senso comum muito restrito a partir do qual se analisa a realidade. Este senso comum é ainda enviesado pela suposta cientificidade do direito que, ao contribuir para a sua despolitização, cria a ficção de uma prática jurídica pura e descomprometida. ${ }^{6}$
\end{abstract}

O que Boaventura descreve é tudo do qual a Defensoria Pública precisa se afastar, não apenas porque somos uma Instituição contrapoder, conforme já citei Caio Paiva, mas porque constitucionalmente somos expressão e instrumento da democracia. Inexiste democracia sem um rol mínimo de direitos humanos fundamentais, e esses direitos são produtos de construçôes históricas e sociais, as quais se travam em campos outros que não apenas no judicial. Portanto, a sistemática de atuação do CRDH/DPE-RS, ao primar e firmar as funçôes institucionais da Defensoria Pública, nos termos do artigo $4^{\circ}$ da LC no. 80/94, vê que o fortalecimento do trabalho em rede, por meio da participaçáo em Conselhos de Direitos e mediante a aproximação e da parceria desenvolvida com os movimentos sociais, suas lideranças e organizações da sociedade civil - os quais são agentes responsáveis pela construção desses direitos -, é o verdadeiro motor da democracia, e o acolhimento integral fornecido empodera e fortalece a cidadania política, permitindo resistência e a continuidade na luta pela defesa dos direitos.

Como salienta Boaventura de Sousa Santos, a Defensoria Pública, dentre outras Instituições do sistema de justiça, é aquela que possui melhores condiçôes de contribuir

$\overline{6}$ SANTOS, B. S. de. Para uma Revoluçáo Democrática da Justiça, 2011. 
para desvelar a procura judicial suprimida, cumprindo aos defensores públicos aplicar no seu quotidiano profissional a sociologia das ausências, reconhecendo e afirmando os direitos dos cidadãos intimidados e impotentes, cuja procura por justiça e conhecimento dos direitos têm sido suprimidos e ativamente reproduzidos como não existentes.

Aí está a revolução da nossa sistemática de atuação, ela permite verdadeiramente uma assistência jurídica que condiz com um acesso a uma ordem jurídica que se requer justa. Ela permite mais do que isso, ela busca efetiva justiça social, o que vai ao encontro de um dos nossos objetivos enquanto razão de existir, que é a redução das desigualdades sociais. E esse é o nosso olhar sistêmico de defensorar.

\section{CONSIDERAÇÓES FINAIS}

Estamos vivenciando um momento político e institucional no país que exige, mais do que nunca, o reafirmar dos ideais democráticos. O sistemático desmantelamento e surrupiamento dos direitos da população mais vulnerável exige uma postura ativa da Instituição Defensoria Pública, pois se é instrumento e expressão do regime democrático está a existir para e pela democracia.

Assim, procurou-se na presente artigo correlacionar a sistemática de atuação do CRDH/ DPE-RS com os objetivos e as funçóes institucionais da Defensoria Pública, dando conta de que a sua forma de defensorar é revolucionária porquanto trabalha com a reconceituação do que seja a Defensoria Pública enquanto Instituição que é.

Mais do que o cumprimento das nossas funçóes institucionais de prestar acolhimento integral, multidisciplinar, de atuar na preservação e reparação dos direitos das vítimas de violência estatal, tortura e, na espécie, da mulher vítima de violência, da assistência jurídica integral e da promoção e difusão e conscientização dos direitos humanos, da cidadania e do ordenamento jurídico, pensamos que o nosso trabalho tem por missão contribuir na construção da própria cidadania, a qual no Brasil vem sendo construída num longo caminho que náo pode se dissociar da sua história, bem como da sua estrutura enquanto sociedade, que, desde a Colônia, traz uma base escravocrata, patrimonialista e elitista, uma vez que de acordo com Carvalho ${ }^{7}$ o fenômeno da cidadania é complexo e historicamente definido, uma vez que o exercício de certos direitos não gera automaticamente o gozo de outros, razão pela qual a cidadania inclui várias dimensóes.

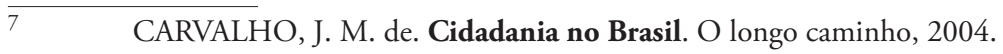


Entendendo com Souki, ${ }^{8}$ no entanto, que cidadania é um método de inclusão social, temos por missão constitucional o dever de providenciar na inclusão dos chamados cidadãos subintegrados, de acordo com Neves, ${ }^{9}$ aqueles que embora lhe faltem condiçóes reais de exercer os direitos constitucionalmente declarados, não estão liberados dos deveres e das responsabilidades do aparelho repressivo estatal, sendo integrados ao sistema jurídico, em regra, como devedores, indiciados, denunciados, réus, condenados, mas não como detentores de direitos.

Boaventura de Sousa Santos ${ }^{10}$ nos convoca para uma revolução democrática da justiça e nós convocamos a Defensoria Pública para uma revolução democrática por meio da sistemática de atuação e de defensorar do CRDH/DPE-RS, pois como o mesmo autor nos enfoca: "sem direitos de cidadania efetivos a democracia é uma ditadura mal disfarçada."

\section{REFERÊNCIAS}

BRASIL. Constituição (1988). Constituiçáo da República Federativa do Brasil. Brasília, DF: Senado Federal, 1988.

\section{. Lei Complementar n ${ }^{\circ} .80 / 94$.}

. Lei Complementar $n^{\circ} .132 / 09$.

CARVAlHO, J. M. de. Cidadania no Brasil. O longo caminho. 5.ed. Rio de Janeiro: Civilização Brasileira, 2004.

SANTOS, B. S. de. Para uma Revoluçáo Democrática da Justiça. 3.ed. São Paulo: Cortez, 2011.

SOUSA, J. A. G. de. (Coord.). Uma Nova Defensoria Pública Pede Passagem. Reflexôes sobre a Lei Complementar 132/09. Rio de Janeiro: Lumen Juris, 2012.

NEVES, M. Entre Têmis e Leviatã: Uma Relação Difícil. O Estado Democrático de

8 SOUKI, L. G. A atualidade de T. H. Marshall no estudo da cidadania no Brasil. Civitas - Revista de Ciências Sociais, 2006.

9 NEVES, M. Entre Têmis e Leviatá: Uma Relação Difícil. O Estado Democrático de Direito a partir e além de Luhmann e Habermas, 2006.

10 SANTOS, B. S. de. Para uma Revoluçáo Democrática da Justiça, 2011 
Direito a partir e além de Luhmann e Habermas. São Paulo: Martins Fontes, 2006.

PAIVA, C. C. Prática Penal para a Defensoria Pública. Rio de Janeiro: Forense, 2016.

ROCHA, A. S. da. Defensoria Pública. Fundamentos, Organizaçáo e Funcionamento. São Paulo: Atlas, 2013.

SOUKI, L. G. A atualidade de T. H. Marshall no estudo da cidadania no Brasil. Civitas

- Revista de Ciências Sociais, v. 6, n. 1, p. 39-58, 2006. 